\title{
RECYCLING, REUSE, TRADITIONAL KNOWLEDGE and INNOVATIVE TECHNIQUES to MITIGATE PLASTIC WASTE POLLUTION ON CAMEROON COASTAL ZONES
}

\author{
Oben Mbeng L. ${ }^{1 *}$, Esome Ismael . ${ }^{1,2}$, Mboglen David. ${ }^{3}$, Ntyam Ondo Sylvie. ${ }^{4}$ \\ ${ }^{1}$ The University of Douala, Institute of Fisheries and Aquatic Sciences at Yabassi, Cameroon \\ ${ }^{2}$ Madiba \& Nature, Douala, Cameroon. \\ ${ }^{3,4}$ Specialized Research Centre for Marine Ecosystems (CERECOMA/ IRAD), Kribi, Cameroon
}

\begin{abstract}
This research paper presents the results of recycling, reuse, traditional knowledge and innovation techniques aimed at mitigating plastic waste pollution on the Cameroon coastal zones. The objective of this research work is to analyze qualitatively and quantitatively solid waste in the West Coast (Limbé) with the South Coast (Kribi), develop a technology based on local knowledge from fishermen to build an ecological boat as well as evaluate local perceptions of the impacts on fishing and tourism. The methodology consisted of beach surveys, interviews and questionnaires administered to fishermen, tourists to determine perception, attitudes and belief on plastic marine waste The results showed a high pollution from plant debris (77.30\%) followed by plastics (20.9\%) and organic food waste (1.8\%) at Limbe Down beach in the Southwest and Londji in the South Regions of Cameroon. There was no significant difference between the two regions regarding perception of pollution on the littoral coast. Amongst the fishery stakeholders, 48\% interviewed recognized an average reduction in income while 100\% of hotel operators revealed it has reduced hotel bookings The reuse and recycling process involved 850 PET bottles of one liter to manufacture an ecological boat that measures $5.5 \mathrm{~m}$ and capable of transporting three persons of $80 \mathrm{~kg}$ each. This innovation used in Londji beach for ecotourism has fascinated many tourists because of its originality. The study reveals that pre-collect, reuse, recycling and traditional knowledge, besides being a primary strategy, is amongst the most effective techniques for reducing the quantity of used PET bottles disposed at our exotic beaches Limbe and Kribi.
\end{abstract}

Keywords: Pollution, Plastic bottles, Innovation, Traditional knowledge, Reuse, Recycling.

\section{INTRODUCTION}

In modern society, plastic has achieved a pivotal status, with extensive commercial, industrial, medicinal and municipal applications. The annual global production of plastics highly increased since the development of synthetic polymers in the middle of the 20th century and has doubled in the last 15 years, being in the order of 280 million tons per year [1]. It has been estimated that plastics account for around $10 \%$ by weight of the municipal waste stream [2] with less than $10 \%$ of the plastic produced being reused or recycled. Through accidental release and indiscriminate discards, plastic waste has accumulated in the environment at an uncontainable rate, where it is subjected to wind and river-driven transport, ultimately reaching the coast. Due to its lightweight, durable nature, plastic has become a prevalent, widespread element of marine litter [3].

PET bottles are an environmental problem for the large cities in Sub-Saharan African Countries. This is due to the rapid population growth, increased urbanization, inappropriate and inefficient waste collection and disposal systems. This has caused environmental pollution and placed an additional burden on those already suffering from urban poverty [4]. The situation is 
worsened because of the systematic failure of policy makers and municipal authorities to identify the most sustainable ways to pre-collect reuse and recycle PET bottles in a manner that is in line with the socio-economic aspirations of the coastal population. In Cameroon, pre-collect, reuse and recycling of Polyethylene terephthalate (PET) bottles has become an environmentally friendly and economical alternative method thus diverting it from beaches and landfills, producing valuable raw materials for innovation and as an income generator. But despite the fact that pre-collect, reuse and recycling are the foundation of sustainable strategy and practice, it has been neglected within integrated sustainable waste management in many Sub-Saharan African countries. It is on this basis that a study was carried out to analyze qualitatively and quantitatively PET bottles recovered from the Londji and Down beaches in Kribi and Limbe municipalities respectively. Traditional knowledge from fishermen was acquired to build an ecological boat, considered an innovative technology in the coastal zones of Cameroon.

\subsection{Sources and Distribution of Plastic Marine Waste}

The increasing problems of plastic marine waste begin on land, where streams and rivers carry them to the coast. Ocean currents then transport these waste to "remote" open ocean ecosystems [5]. Through accidental release and indiscriminate discards, plastic waste has accumulated in the environment at an uncontrollable rate, where it is subjected to wind and river-driven transport, ultimately reaching the coast [6]. Annually, more than 35 million plastic bottles and 500 billion plastic bags are used by consumers, many of which end up in oceans and along beaches [7]. The accumulation of plastics in the environments is a result of improper disposal or shipping spills. Since they are lightweight and durable, plastics are capable of travelling long distances; ending up in terrestrial environments, along shorelines, or floating in the open ocean [8]. Plastic wastes also end up in the marine environment when accidentally lost, carelessly handled or left behind by beachgoers. They also reach the sea as litter carried by rivers and municipal drainage systems. There are major inputs of plastic litter from land-based sources in densely populated or industrialized areas, most in the form of packaging [9]. Some common types of plastic wastes [10] are shown in Table 1.

\section{Table 1. Some common types of plastic wastes [10]}

\begin{tabular}{|l|l|l|}
\hline \multicolumn{1}{|c|}{ Acronym } & \multicolumn{1}{|c|}{ Full name } & \multicolumn{1}{c|}{ Common examples } \\
\hline PETE/PET & Polyethylene terephthalate & Soda bottles, Films, \\
\hline HDPE & High density polyethylene & $\begin{array}{l}\text { Milk jugs, Packaging, Shampoo bottles, Yogurt containers, } \\
\text { Detergent bottles, Shopping Bags }\end{array}$ \\
\hline PVC & Polyvinyl chloride & $\begin{array}{l}\text { Clear food packaging, Candy wrappers, Some bottles, } \\
\text { Water pipes, Curtains, Credit card, Packaging films, Water } \\
\text { films }\end{array}$ \\
\hline LDPE & Low density polyethylene & Plastic bags, Wire cloth, Squeezable bottles, Shopping bags \\
\hline PP & Polypropylene & Caps, straws, Some bottles, Plastic bag and toy, Drinking straws \\
\hline PS & Polystyrene & $\begin{array}{l}\text { Takeout food containers, Disposable cups \& plates, } \\
\text { Fast food boxes, CD cases, }\end{array}$ \\
\hline PC & Polycarbonate & Water jugs, DVDs, Sunglasses, \\
\hline PA & Polyamide/Nylon & Toothbrushes \\
\hline
\end{tabular}

\subsection{The Cameroon Coastal Zones}

Cameroon has great potential with $420 \mathrm{~km}$ of maritime coast (Fig. 1), mangrove forest, lagoons and many beaches and described as 'LUNGS' of the economy. This is due to their high productivity, lodging a majority of the economic activities [11]. Kribi is a coastal town and the economic capital of the South Region of Cameroon, with Kribi 1 municipality having 33,298 inhabitants and Kribi II 39,156 inhabitants. Limbe is a coastal town and an economic capital of the South-West Region of Cameroon. It has a population of about 150,000 inhabitants [12]. A larger part of the population is made up of indigenous 
people and local fishermen who are mostly foreigners, uneducated and with very little knowledge and perceptions of plastic marine waste as a veritable pollutant of the Cameroon coast.

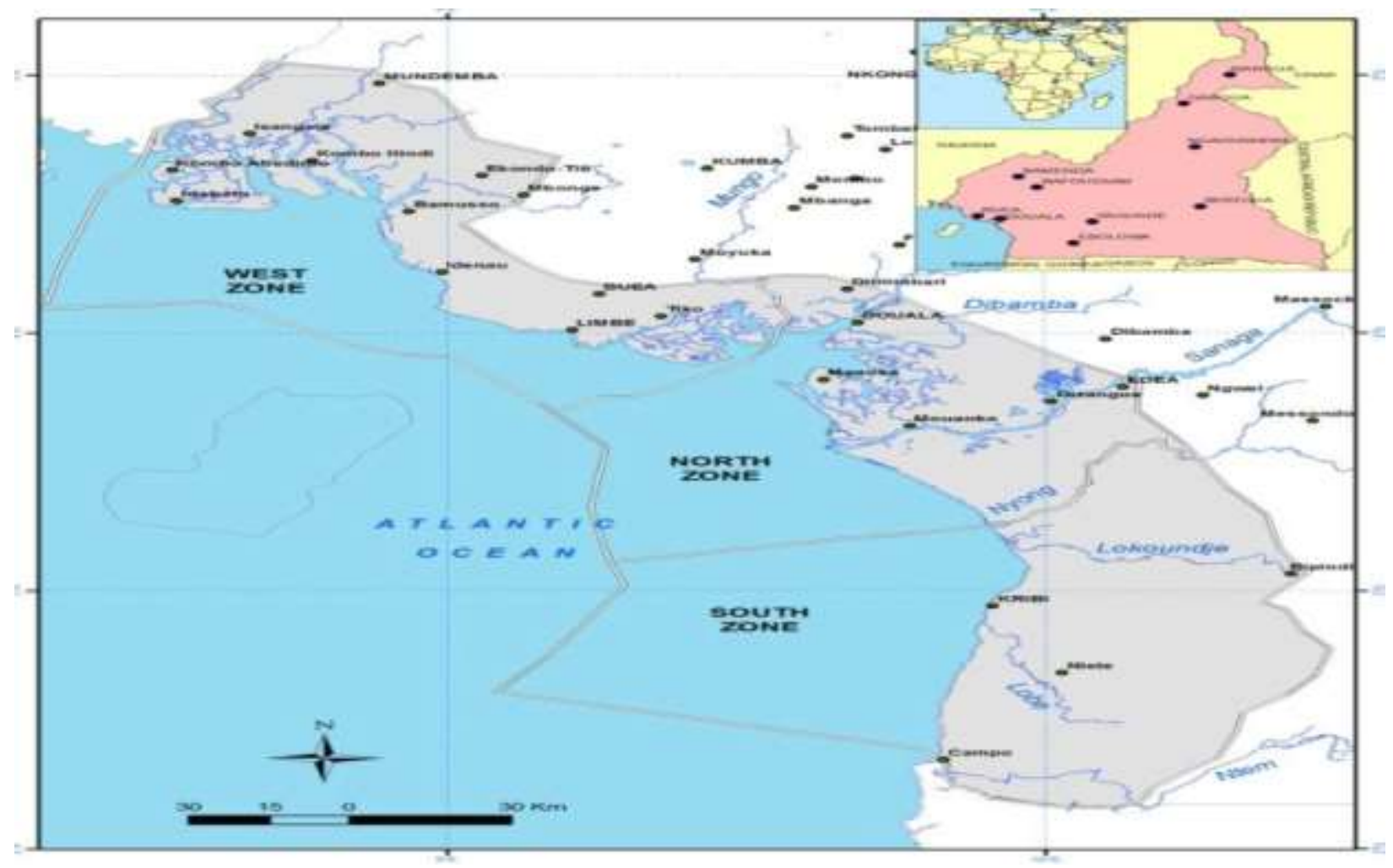

Figure 1. Cameroon coastline [13]

\subsection{Sociocultural Groups in Kribi -South Region of Cameroon}

According to Decree No. 2007/115 of April 23, 2007, the municipalities of Kribi I has a population of 33298 and Kribi II, 39 156. This part of the country has a low population density of about 10 persons per square kilometer. The socio-cultural groups in this area are classified into 6 major ethnic groups:

- Bulu, mainly farmers and hunters, between Kribi and Mefo;

- Ntoumou, mainly farmers and hunters, between Mefo and Mvi'ilimengale;

- Batanga and Yassa, coastal populations, mainly fisherman, between Kribi and Campo;

- Mabea, farmers, hunters, fishermen established in the village of Mabiogo;

- Mvae forest peoples, hunters, farmers and fishermen between Bouandjo and Itonde;

- Bagyeli (pygmies) nomadic populations, they live from hunting and gathering.

Apart from the Batanga and Mabéa who are indigenous in the region, we also note the presence of foreign communities.

On the economic level, the inhabitants derive most of their income from activities stemming from the primary, secondary and tertiary sectors, with the predominance of fishing activity. These activities include: Agriculture, fishing, logging, tourism, hunting, sand extraction and industrial activities.

\subsection{Sociocultural Groups in Downbeach Limbe -South West Region of Cameroon}

Downbeach Limbe is a fishing dock with a cosmopolitan population [14]. This population consists of Bantu who have cultural traits of resemblance to the coastal population of the littoral region. The most spoken language is English because the city was under British colonial rule, French, Pidgin-English, and other traditional languages (Bakweri, Bouda, Bakosi, Ewondo, Bassa etc ..). The main activity of the population is agriculture with the CDC as the main economic nucleus. The fishing and commercial 
International Journal of Advances in Scientific Research and Engineering (ijasre), Vol 5 (6), June-2019

activities of smoked fish are mostly concentrated at the coast. As for the local population, the majority of men are fishermen or owners of canoes. Some of them are more involved in the construction and maintenance of boats, nets and or maintenance of outboard motors. The vast majority of women are present in the smoking and distribution of fresh and smoked fish "Bonga" (local and current name). On the basis of these anthropogenic activities and their impact on coastal environment we carried out a qualitative and quantitative analysis of plastic bottles for reuse and recycling. With traditional knowledge from fishermen, we built an ecological boat.

\section{METHODOLOGY}

The methodology consisted of interviews conducted with fishermen and tour operators on the impact of plastic marine waste on the beaches. A survey was conducted with 40 persons randomly selected between the ages 19 and 60 (20 fishermen, 10 tourism operators, and 10 residents). Of importance were perception of marine and beach pollution, the types of solid waste encountered and sociocultural and economic impacts on fishing activities. This was followed by direct observation, precollect and beach cleaning (Fig. 2) and characterization of the solid waste on a linear transept between 100-1000m. Weighing of the different waste fractions using a mechanical balance (Fig 3), segregated the waste into 5 categories of plastic waste (PET, PP, PVC, PS, PA), glass, iron, wood, paper and cartons. Traditional knowledge involving a traditional fastening techniques was used to assemble 850 PET bottles of one liter in blocks of 10 to produce an ecological boat (Fig.4) that measures $5.5 \mathrm{~m}$ lenght and capable of transporting three persons of $80 \mathrm{~kg}$ each. The ecological boat has three sections (floor and two borders). The floor was first built, followed by both sides and seats, and finally the assembly. A minimum of one week and a work force of three persons were involved in the production of an ecological boat .

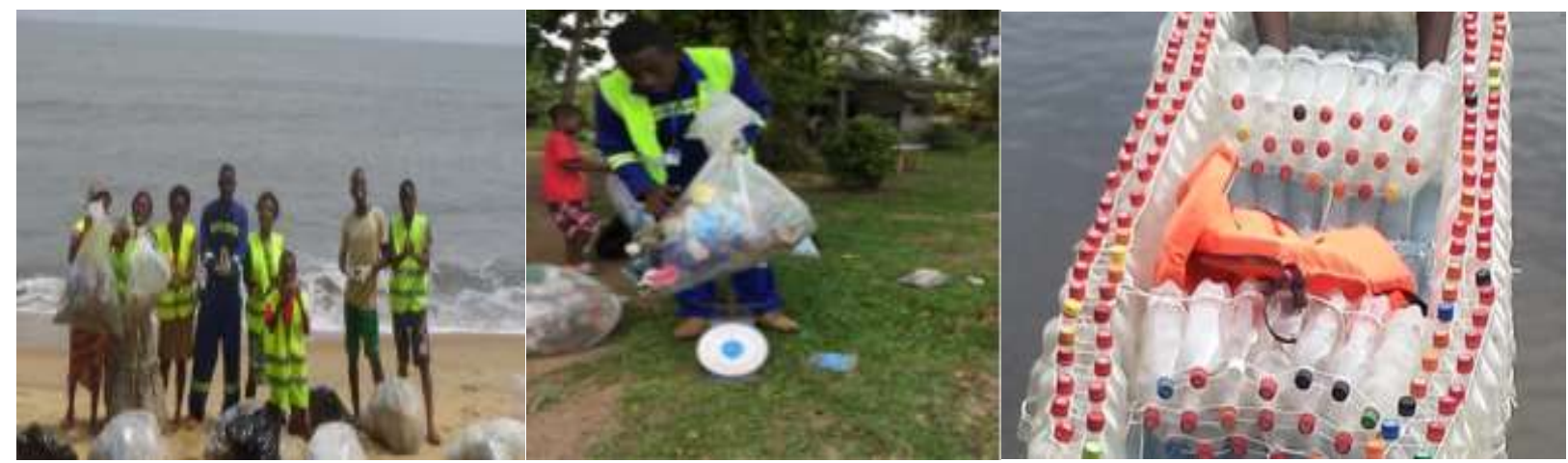

Fig. 2:Pre-collect \&Beach cleaning Fig.3.Weighing of solid waste Fig.4: Ecological boat

\section{RESULTS AND DİSCUSSION}

The waste characterization study revealed that the majority of the recovered solid waste from both the Kribi and Limbe beaches were organic material with an average percentage composition of (77.30\%) followed by plastics (20.9\%). Figures 5 and 6 illustrates the typology and the average percentage compositions for both the plastic and organic wastes respectively. 


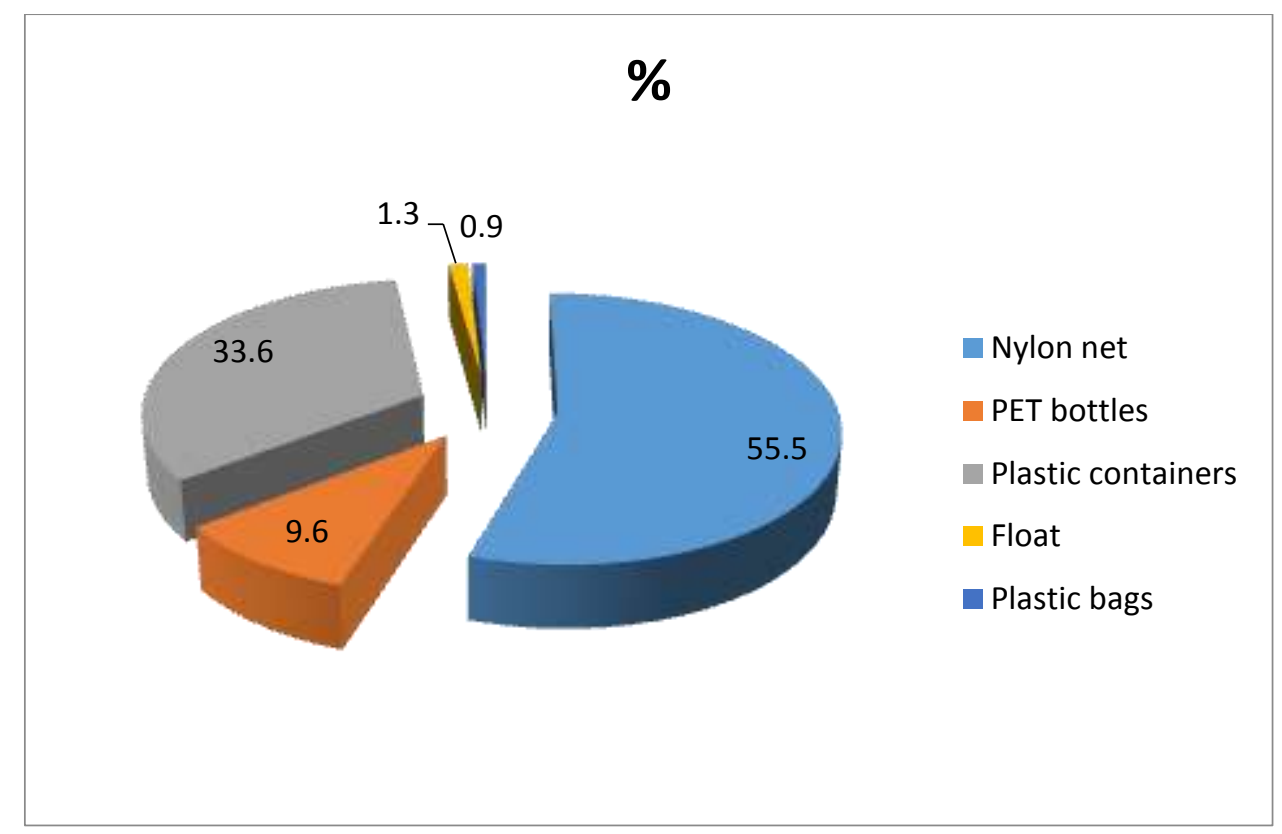

Figure 5. Average percentage composition of plastic waste

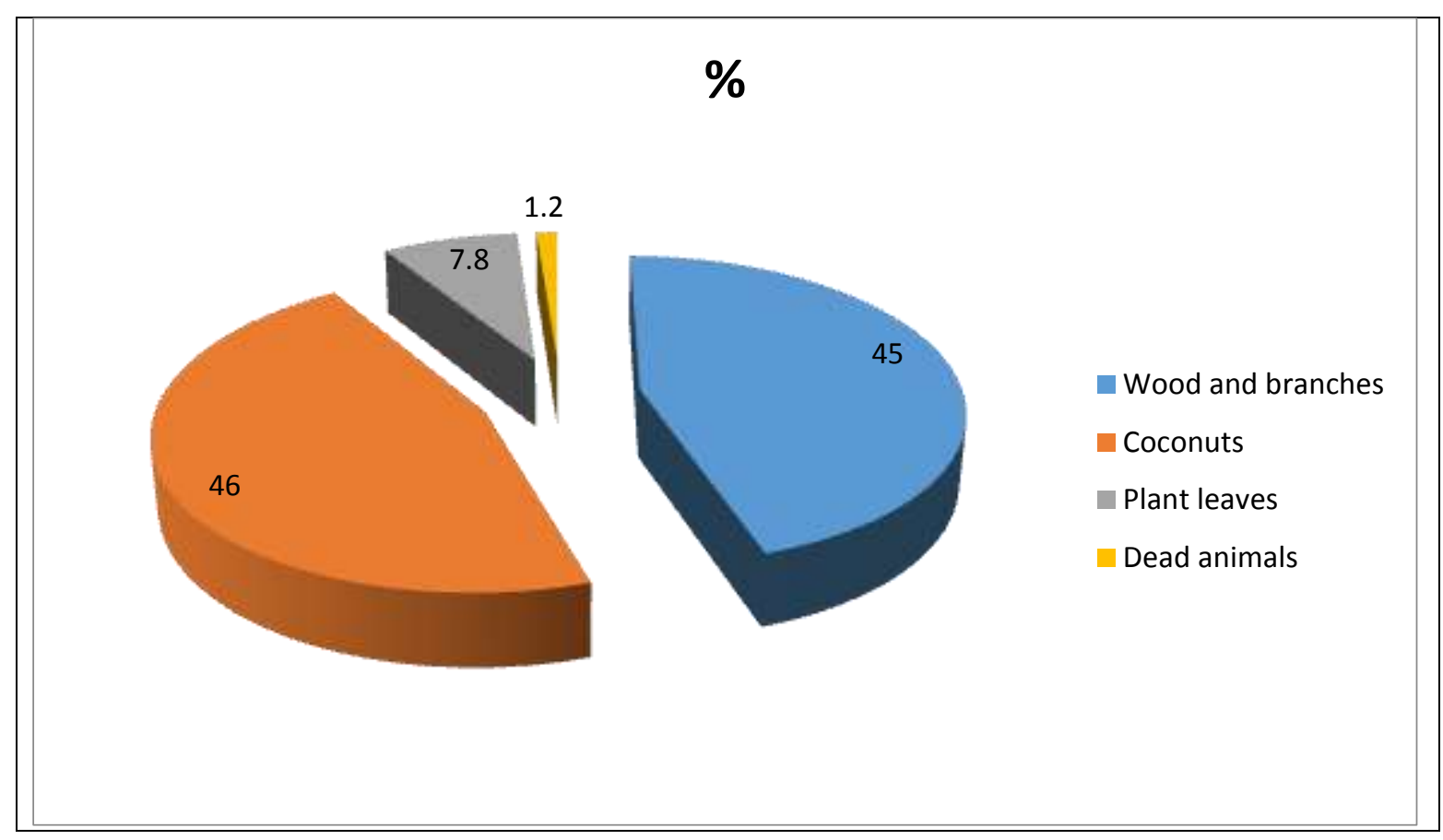

Figure 6. Average percentage composition of organic waste

Beach clean-up campaign revealed a majority of wood waste (19.2\%), plastic waste (19.4\%) and Paper (19.4\%) from Londji beach in Kribi (Fig. 7). We registered wood (20\%), plastic waste (24\%) and Paper (21\%) from Downbeach Limbe (Fig. 8). The presence of wood at these beaches could be linked to the indescriminate logging of the rich mangrove forests along the coastlines by fishermen for use to build makeshift houses and to smoke fish. It must be noted that the Cameroon coastline is heavily populated with numerous economic activities coupled with the many beautiful beaches that are frequently visited by both national and international tourists. The plastics and paper are due to poor behavioural attitudes such as littering from both the tourists and fishermen for which reason a behaviour change can reverse the trend. 


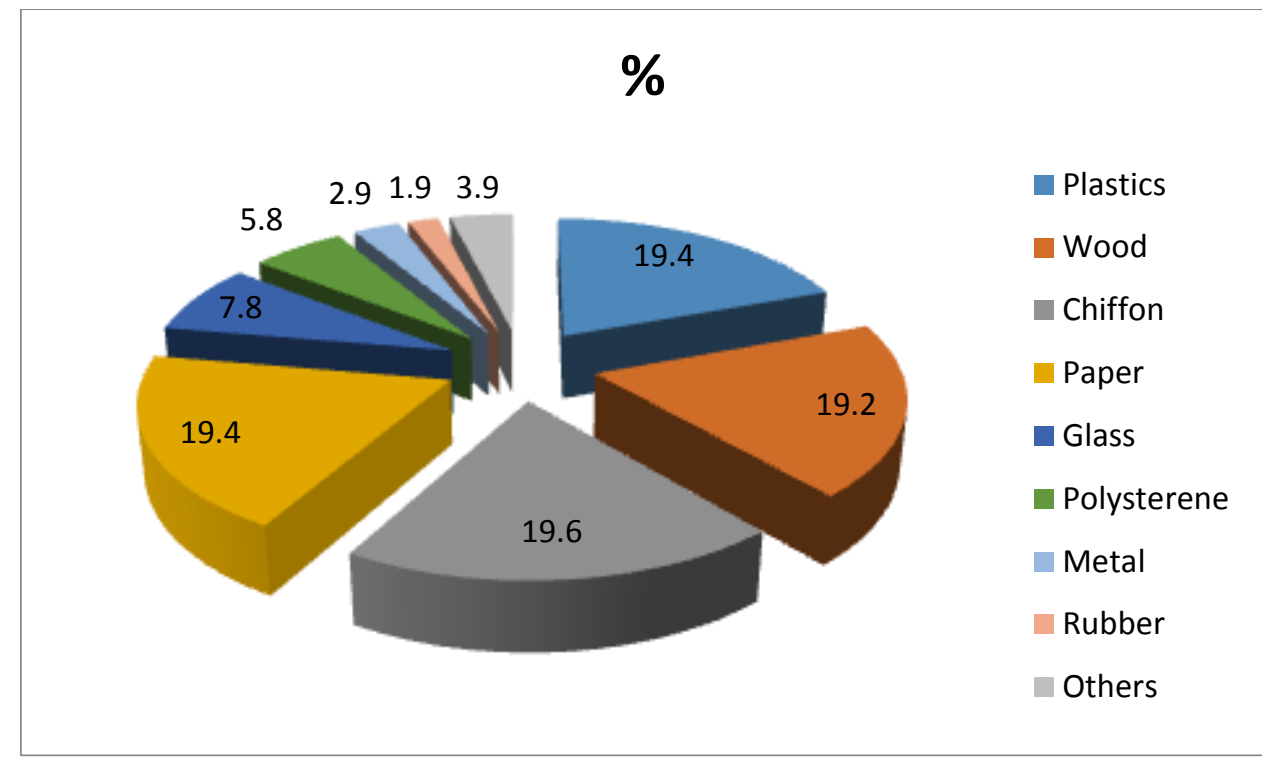

Figure 7. Average \% waste composition from beach cleaning- Londji beach-Kribi

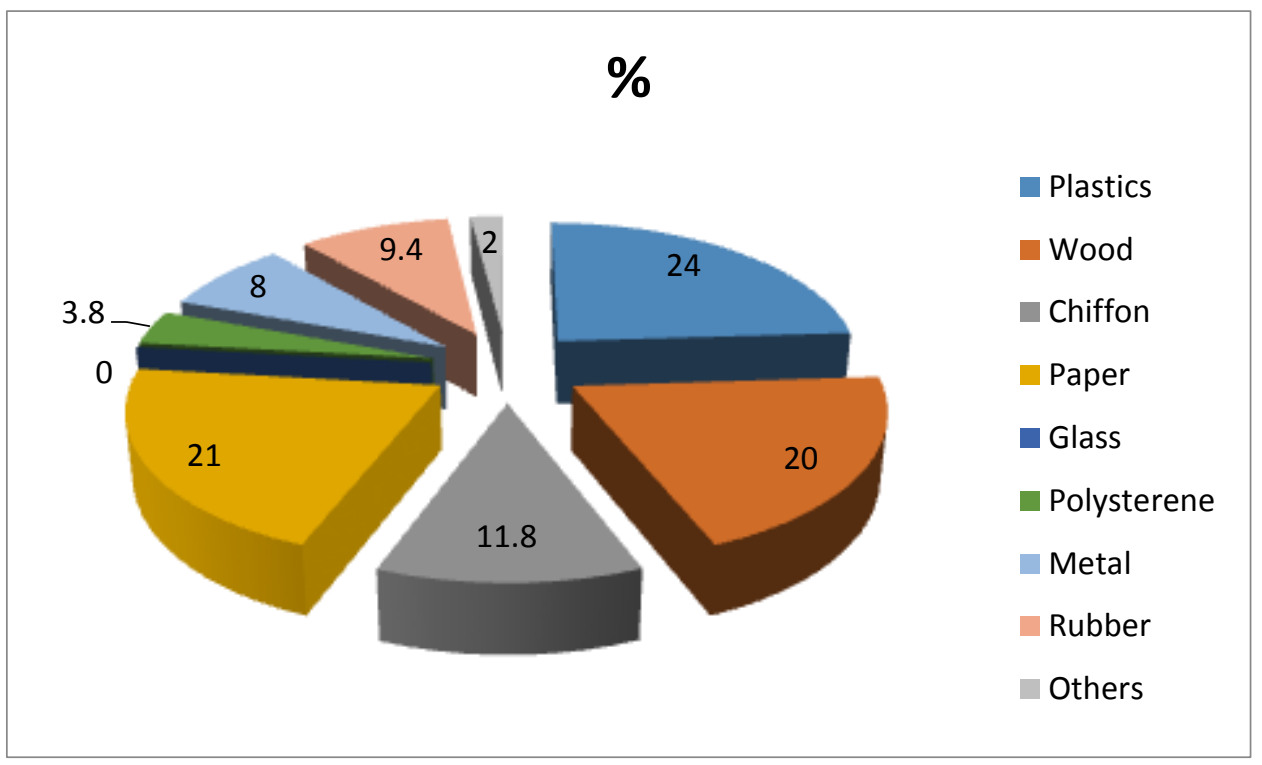

Fig 8. Average \% waste composition from beach cleaning-Downbeach Limbe

Perception of the impact of solid waste pollution on fishing in the South coast (Londji) and the West Coast (Limbe) did not differ significantly $(\mathrm{P}>0.05)$. Fishermen in the West and South coast had a good knowledge of coastal marine pollution indicating that more than $40 \%$ come from the continents. All respondents indicted that beach litter interupts fishing activity. The large proportion of fishermen $(88,2 \%)$ in both the West Coast -Limbe and South Coast -Kribi indicated that plastic marine waste damages the fishing nets and boats with a reduction in catch and income. However only $50 \%$ of tourists operators said waste on beaches had a negative impact on tourism with regards to bookings and beach visits. More than $48 \%$ of fishermen in Limbe and Londji reported an average reduction in income from damages to fishing nets and boats. These results are different from those obtained by [14] on the West Coast of Cameroon where Chinese trawlers and marine currents were responsible for beach pollution. The tourism sector was also impacted by the fact that many of the inhabitants along these coastlines lacked lantrines with the the prevalence in faecal materials along the beaches. 
International Journal of Advances in Scientific Research and Engineering (ijasre), Vol 5 (6), June-2019

Reuse and recycling of PET bottles to an ecological boat is an innovation that has brought to light a new technique of manufacturing boats. The choice of the number of places, and the dimensions namely its length (5.5 m) and its width (0.7 m) was inspired by direct observations from the building of artisanal boats by Nigerian fishermen and traditional knowledge acquired during focus group discussions. Notwitstanding, although the ecological boat has the same dimensions as the artisanal boats and accomodates many people, it does not move at the same speed as the artisanal boat. Notwitstanding, it has been tested only with the tourist (10 persons) along the sea shore in Londji and considered an innovative approach for mitigating the Cameroon coastline from plaste waste pollution and restoration of the marine environment.

\section{CONCLUSION}

This present study on Cameroon coastal zones has enabled us to know qualitatively and quantitatively the different types of solid waste in Downbeach Limbe of the West Coast and Londji beach in the South coast. The results obtained shows that solid waste pollution on the Cameroonian coast has a negative effect on several activities especially fishing and tourism. Reuse and recycling of PET bottles into an ecological boat is being currently used for sightseeing tours in Londji. It attracts tourists because of its originality for use in ecotourism. The study has revealed that pre-collect, reuse and recycling besides being a primary strategy, is amongst the most effective techniques for reducing PET bottles dumped at beaches and landfill sites and a tool for fighting marine pollution and destruction of the fragile mangrove ecosystems on the Cameroon coastaline.

\section{REFERENCES}

1. PLASTICS EUROPE, (2010).”Plastics Europe's Views on the Marine Litter Challenge,” April 2010, pp. 3.

2. D.K.A Barnes, F. Galgani, R. C. Thompson and M. Barlaz, (2009). "Accumulation and fragmentation of plastic debris in global environments," Philosophical Transactions of the Royal Society”, 364: 1985-1998.

3. R.C. Thompson, F.S Moore, Vom Saal and S.H. Swan, (2009). "Plastics, the environment and human health: current consensus and future trends," Philosophical Transactions of the Royal Society," 364: 2153-2166.

4. JICA, (2005). "Supporting Capacity Development in Solid Waste Management in Developing Countries," Towards Improving Solid Waste Management Capacity of Entire Societies- (July 2005. pp. 218.

5. A. L. Andrady, (2011). "Microplastics in the marine environment," Mar. Pollut. Bull., 62 (8): 1596-1605.

6. S. L. Wright, C. T Richard. and S. G. Tamar,a, (2013). "The physical impacts of microplastics on marine organisms," A review. Environ. Pollut., 178: 483-492.

7. What a Waste, (2010). "Plastic Oceans," Retrieved from http://www. Plasticoceans.net/the-facts/what-a waste.

8. M. Zbyszewski, and P. L. Corcoran, (2011). "Distribution and degradation of fresh water plastic particles along the beaches of lake Huron, Canada," Water, Air Soil Pollut., 220 (1): 365-372.

9. M. R. Gregory, (1999). "Plastics and South Pacific Island shores: environmental implications," Ocean and Coastal Manag., 42: 603-615.

10. R, P. Pawar, S. S. Sanket and B. P Rahul, (2016). "Plastic marine debris: Sources, distribution and impacts on coastal and ocean biodiversity," PENCIL Publication of Biological Sciences Vol. 3(1):40-54.

11. M.T. Agardy, (1994). "Advances in marine conservation: the role of marine protected areas," Trends in Ecology and Evolution, 9: 267--270.

12. National Institute of Statistics, (2007). "Evolution of National Statistical Systems in Cameroon," National Institute of Statistics: Yaoundé, Cameroon.

13. SNH. (2009). "L'Elaboration d'un programme de suivi de la vitalité des mangroves Camerounais, " Rapport Projet CAPECE/CPSP/SNH. 128pp.

14. J. Folack, (1989). "Etude préliminaire du phytoplancton d'une zone côtière d'exploitation crevetticole Kribi-Cameroun," Cam. j Biol. Bioch. Sc. 2(1), pp. 51-65. 